\title{
УГЛЕВОДОРОДНАЯ КОРРОЗИЯ ПИРОЛИЗНЫХ ПЕЧЕЙ
}

При переработке легкой фракции нефтяных пиролизных смол на сланцеперерабатывающих предприятиях выявилось агрессивное воздействие ее на металл труб печей пиролиза (сталь ОХ23Н18). Разрушение металла наблюдалось в радиантной секции печи, где температура потока достигала $670-700^{\circ} \mathrm{C}$. Разрушения имели вид выемок с ярко выраженной формой полусферы диаметром до нескольких миллиметров с острыми краями по плоскости разреза металла по месту повреждения. Изучение химического состава и механических свойств металла в местах повреждения показало значительное повышение содержания углерода и повышение твердости его на поверхности повреждения по сравнению с основным металлом [ $\left.{ }^{1}\right]$.

В течение года только на одной печи пиролиза произошла 21 аварийная остановка в результате повреждения труб радиантной секции, что сократило выпуск продукции и привело к дополнительным материальным и трудовым затратам.

Изучение агрессивных примесей сырья показало, что кислотность его колеблется в пределах $0,4-3,5$ мг-экв/ , содержание хлоридов $0,8-3,2$ мг/л и серы - $0,01-0,1 \%$.

Учитывая относительно низкое содержание агрессивных примесей и отсутствие связи между их содержанием и скоростью коррозии как в лабораторных, так и в промышленных условиях, а также температурные условия процесса и особый характер повреждений, можно сделать вывод, что имеет место совершенно новое проявление агрессивного действия углеводородного сырья на металл, которое ранее в литературе не описано.

Для объяснения этого явления были организованы лабораторные исследования. Лабораторная установка включает систему дозировки сырья, кварцевый изотермический реактор и систему конденсации. Температура пиролиза была $700^{\circ}$. Количество кокса определялось взвешиванием. Сырье и продукты анализировались хроматографически на «Цвет-4» с пламенно-ионизационным детектором. Коррозионная активность сырья оценивалась весовым методом.

Изучение процесса пиролиза показало колебание скорости коррозии в широких пределах от 0 до $97 \mathrm{e} / \mathrm{s}^{2} \cdot \varkappa$. Анализ продуктов пиролиза показал определенную зависимость между их составом и агрессивностью процесса. Так, при агрессивном процессе по сравнению с неагрессивным наблюдалось пониженное содержание непредельных углеводородов и метана и повышенное содержание водорода в пиролизном газе, повы- 


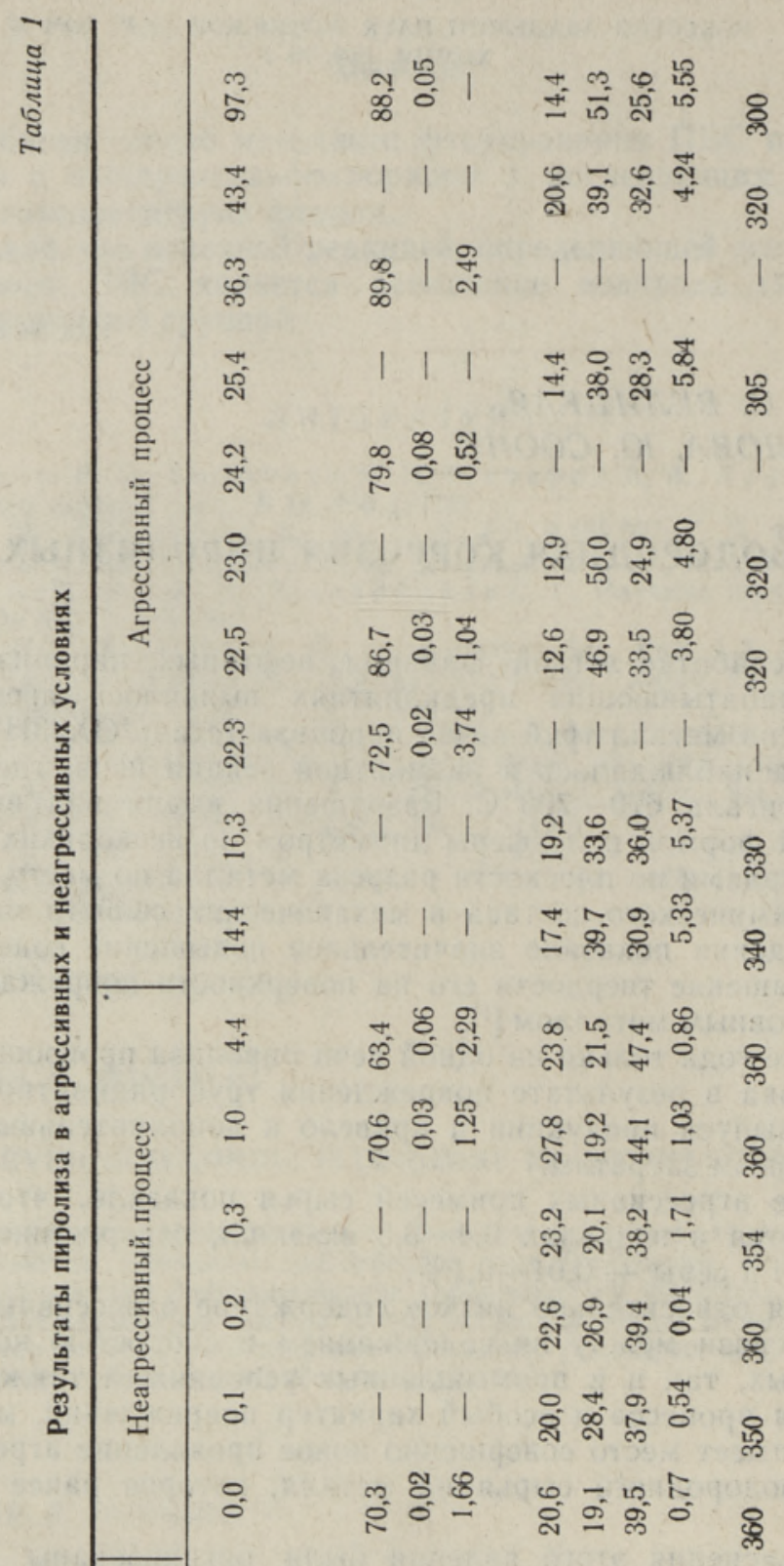

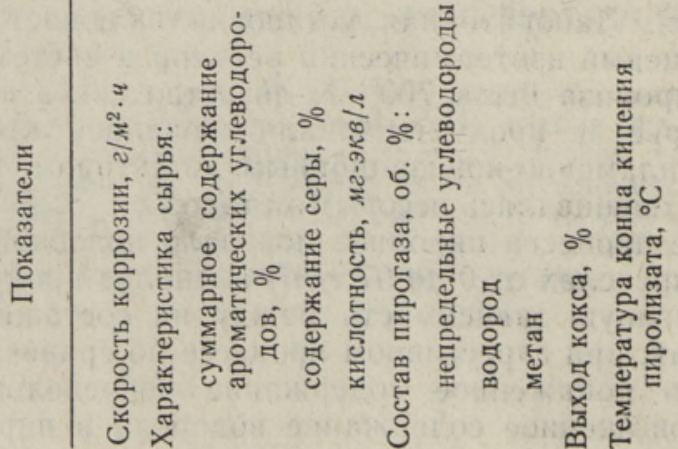




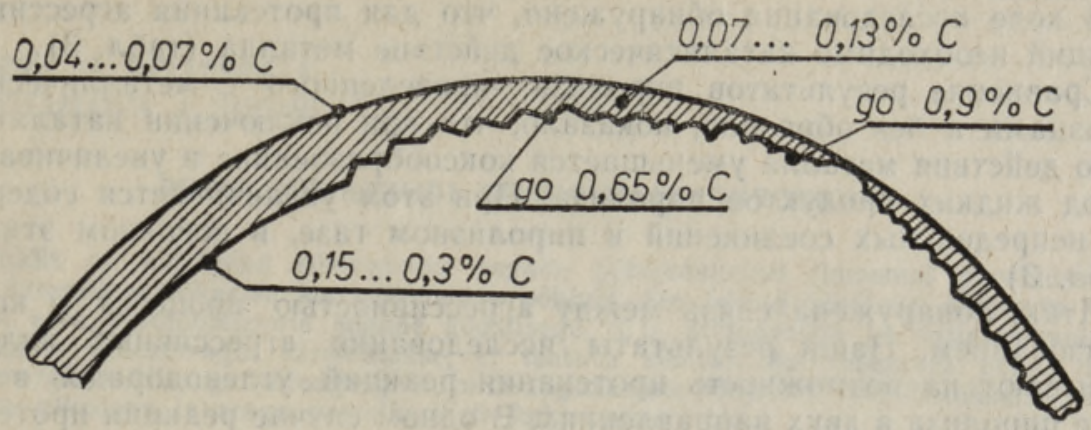

Характер разрушений трубы пиролизной печи-и содержание углерода в различных слоях ее сечения.

таблица 2

Характеристика кокса

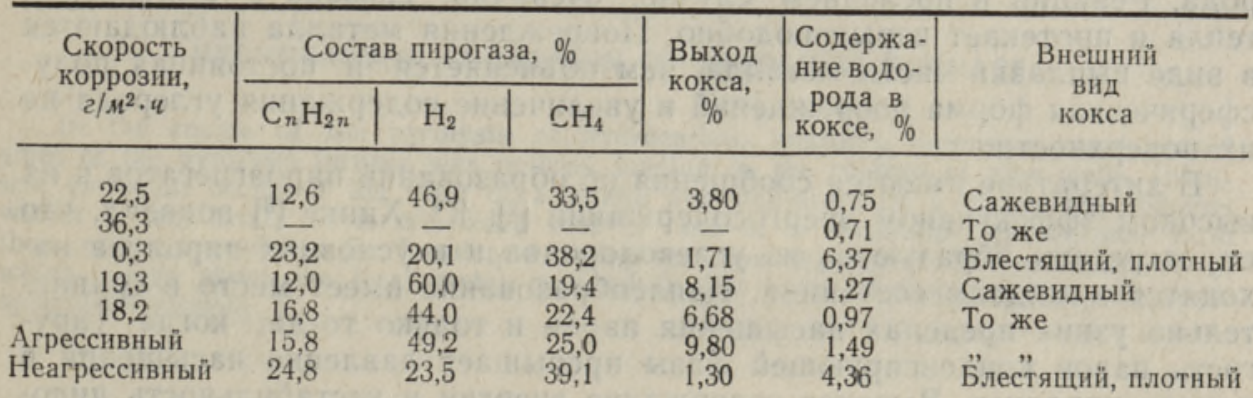

Таблица 3

Каталитическое воздействие металла на состав и выход продуктов пиролиза

\begin{tabular}{|c|c|c|c|c|c|c|c|c|c|}
\hline \multirow[b]{2}{*}{ Опыт } & \multicolumn{6}{|c|}{ Газ, \% } & \multicolumn{2}{|c|}{ Кокс } & \multirow{2}{*}{ 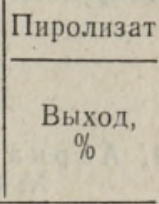 } \\
\hline & $\mathrm{C}_{2} \mathrm{H}_{4}$ & $\mathrm{C}_{3} \mathrm{H}_{6}$ & $\left|\begin{array}{c}\text { Бутен } \\
+ \\
\text { изо- } \\
\text { бутен }\end{array}\right|$ & $\mathrm{H}_{2}$ & $\mathrm{C}_{n} \mathrm{H}_{2 n}$ & $\mathrm{CH}_{4}$ & $\begin{array}{c}\text { Вы- } \\
\text { ход, } \\
\%\end{array}$ & 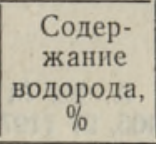 & \\
\hline $\begin{array}{l}\text { C образцами } \\
\text { Без образцов } \\
\text { C образцами } \\
\text { Без образцов } \\
\text { Без образцов }\end{array}$ & $\begin{array}{r}8,1 \\
15,7 \\
13,0 \\
- \\
-\end{array}$ & $\begin{array}{l}6,5 \\
8,7 \\
4,3 \\
- \\
-\end{array}$ & $\begin{array}{l}1,6 \\
1,7 \\
1,1 \\
- \\
-\end{array}$ & $\begin{array}{l}18,0 \\
25,4 \\
19,8 \\
23,0 \\
24,0\end{array}$ & $\begin{array}{l}44,2 \\
23,4 \\
37,3 \\
24,4 \\
22,6\end{array}$ & $\begin{array}{l}28,8 \\
39,2 \\
33,8 \\
39,2 \\
38,5\end{array}$ & $\begin{array}{l}9,8 \\
1,3 \\
5,0 \\
1,6 \\
0,84\end{array}$ & $\begin{array}{l}1,49 \\
4,36 \\
- \\
-\end{array}$ & $\begin{array}{l}74,6 \\
81,5 \\
78,4 \\
80,0 \\
85,0\end{array}$ \\
\hline
\end{tabular}

шенный выход кокса, а также пониженное содержание тяжелых углеводородов в пиролизате (табл. 1).

Кокс, получаемый при агрессивном процессе, сажевидный и содержит меньше водорода, чем блестящий плотный кокс, выделяющийся при неагрессивном процессе (табл. 2).

Анализ углеводородного состава и примесей разного сырья показал, что трудно выделить какое-нибудь соединение, содержание которого определяло бы агрессивность процесса. Однако можно сказать, что в пределах концентрации примесей $30-33 \%$ к ароматическим углеводородам (сумма бензола, толуола, ксилолов, этилбензола, стирола) процесс является преимущественно неагрессивным. 
В ходе исследования обнаружено, что для протекания агрессивных реакций необходимо каталитическое действие металла (табл. 3).

Сравнение результатов пиролиза, проведенного с металлическими образцами и без образцов, показало, что при исключении каталитического действия металла уменьшается коксообразование и увеличивается выход жидких продуктов пиролиза. При этом увеличивается содержание непредельных соединений в пиролизном газе, в основном этилена (табл. 3).

Итак, обнаружена связь между агрессивностью процесса и коксообразованием. Наши результаты исследования агрессивных явлений указывают на возможность протекания реакций углеводородов в процессе пиролиза в двух направлениях. В одном случае реакция протекает преимущественно как крекинг углеводородов с низким выделением водорода, кокс образуется как продукт уплотнения ароматических, углеводородов и содержит значительное количество водорода (неагрессивный процесс). В другом случае наблюдается увеличенное содержание водорода в газе, кокс похож на сажу с небольшим содержанием водорода. Реакция в последнем случае, очевидно, связана с выделением тепла и протекает взрывоподобно. Повреждения металла наблюдаются в виде выплавки части металла, чем объясняется и постоянная полусферическая форма повреждений и увеличение содержания углерода на их поверхности.

В литературе имеются сообщения об образовании пироагрегатов и их высоком эффективном энергосодержании [2]. Ю. Хинке [3] показал, что пироагрегаты образуются из углеводородов и в условиях пиролиза находятся в жидком состоянии. Каплеобразование имеет место в сравнительно узких пределах насыщения паров и только тогда, когда упругость паров конденсирующей фазы превышает давление насыщения в камере пиролиза. Высокое содержание энергии и нестабильность пироагрегата позволяют заключить, что при соприкосновении пироагрегата с поверхностью металла происходит спонтанное выделение энергии, которое приводит к местному выплавлению капли металла и образованию повреждений полусферической формы.

\section{ЛИТЕРАТУРА}

1. А арна А. Я., Мазинг Ю. К., Тедер Ю. Т. Тр. Таллинск. политехн. ин-та, № 405, 27 (1976).

2. Sütterli n, L., Ber. Kernforschungsanlage Jülich, 735-RW (1971).

3. Hi nke, J., Ber. Kernforschungsanlage Jülich, 1156 C (1975).

Таллинский политехнический институт

Ннститут сланцев

Сланцеперерабатывающцй комбинат им. В. И. Ленина
Поступила в редакцию 15/IX 1976 
A. AARNA, O. VELITSKAJA,
E. MIHHAILOVA, J. SOONE

\section{PUROLUUSIAHJUDE SUSIVESINIKKORROSIOON}

Artiklis on käsitletud süsivesinike segude pürolüüsimisel ilmnenud pürolüüsiahju torude intensiivse lokaalse korrodeerumise pōhjusi. On tehtud kindlaks niisuguse korrosiooni seos pürolüüsitavate segude koostisega, s. o. aromaatsete ja mittearomaatsete süsivesinike vahekorraga. Järeldatakse, et teatava süsivesinike vahekorra puhul tekib suure energiasisaldusega püroagregaat, mille lagunemine pōhjustab metalli lokaalse väljasulamise tilkadena ja seega poolsfääriliste kahjustuste tekke.

A. AARNA, O. VELITSKAYA,

E. MIKHAILOVA, J. SOONE

\section{HYDROCARBON CORROSION OF PYROLYSIS FURNACES}

In the course of the pyrolysis of hydrocarbon mixtures, intensive corrosion of pipes of the pyrolysis furnace was noticed, leading to the rupture of pipe walls. Intensive corrosion occurs if the ratio of aromatic and non-aromatic hydrocarbons remains within certain limits. It is concluded that in case of a favourable hydrocarbon ratio there exist prerequisites for forming a high-power pyroaggregate, the decomposition of which brings about the local metal melt-out in the form of drops and causes semispherical damages. 